from Philosophy and Phenomenological Research 65 (2002): 604-628

first presented at the Chisholm Memorial Conference

Brown University, November 10, 2000

\title{
The Good Life: A Defense of Attitudinal Hedonism
}

\author{
Fred Feldman \\ University of Massachusetts, Amherst
}

\section{The Good Life}

The students and colleagues of Roderick Chisholm admired and respected Chisholm. Many were filled not only with admiration, but with affection and gratitude for Chisholm throughout the time we knew him. Even now that he is dead, we continue to wish him well. Under the circumstances, many of us probably think that that wish amounts to no more than this: we hope that things went well for him when he lived; we hope that he had a good life.

But reflection on this hope may lead some of us to ask a question: precisely what feature must Chisholm's life have had in order for that life to have been a good one? What would have made his life one well worth living?

On this question there is much puzzlement and many suggested answers. Nowadays one of the most popular answers is that a person's life goes well if he gets what he wants. (Or perhaps that he gets what he really would have wanted if he had thought about it carefully.) According to a currently somewhat less popular answer, what makes a person's life go well is that he enjoys what he gets. On this view, it does not matter essentially whether the person had any desire for the things he enjoyed prior to his receipt of them, nor does it matter whether he even would have had a desire for them if he had reflected on them. The whole question is whether he enjoyed these things when he got them. Of course, there are many different ways in which we can understand the notion of enjoyment. For each such way, there is a variant of the answer. Each of these constitutes a different way of spelling out a single main idea: a person's life goes well if he enjoys what he gets.

Let us say that any view is a form of "hedonism" if, according to that view, what makes a life go well for the one who lives it is fundamentally a matter of enjoyment. The one who lives

\footnotetext{
${ }^{1}$ Richard Brandt has defended versions of this view. See, for example, pp. 126-9 of his A Theory of the Good and the Right. This general approach to individual welfare is subjected to insightful critical discussion in Chapter 3 of Robert Adams' Finite and Infinite Goods. Adams focusses on the version of the view defended by Sidgwick.
} 
the life enjoys, or "takes pleasure in", the things that befall him in that life. That's the sort of view I will be discussing here.

I have several goals. One is to distinguish among several forms of hedonism. Another is to consider some of the classic objections to hedonism. I want to show that while some of these objections might be effective against some naive forms of hedonism, they are irrelevant to other forms. I will be suggesting that one particular form of hedonism survives all the main objections. For those who do not share my axiological intuitions, I will describe other forms of hedonism that they may find more attractive. I will close by discussing some unfinished business. I will mention some problems that remain even if one of my preferred forms of hedonism can overcome the classic objections here considered.

Before turning to the theories and arguments, however, I need to say a few words about some of the concepts that figure centrally in what follows.

\section{Pleasure as a "Feeling" vs. Pleasure as an Attitude}

2a. Pleasure as a "feeling". Discussions of hedonism often proceed on the assumption that pleasure is some sort of "feeling", or sensation. Perhaps it is thought that pleasure is distinctive sort of sensation - one that we invariably enjoy, or seek, or try to prolong. Perhaps (on the other hand) it is thought that there is no such distinctive feeling of pleasure. On this view, the word 'pleasure' properly applies to feelings of various sorts All that is required is that the one who experiences the feeling enjoys it, or takes pleasure in it ${ }^{-}$For present purposes I can be neutral on this question about the nature of pleasure as a feeling. ${ }^{-}$Nevertheless, I will need to say a few more things about it.

It seems to me that if we use the word 'feeling' strictly and literally, we use it in such a way that something counts as a feeling only if it is something we can really feel, or sense. Consider, for example, a feeling of pressure on your back when getting a massage. In such a case there is an immediate sensory quality - the feeling of pressure on the back. That's a paradigm case of a feeling. Consider, for another example, the feeling of heat in your foot when you first step into a hot bath. That feeling of heat is another paradigm example of a feeling. If pleasure were strictly and literally a feeling, it would be relevantly like these feelings of heat and cold and pressure.

Other strict feelings include an assortment of tickles and itches, tingles and shocks, burnings and freezings. In some cases we identify a feeling by mentioning a typical cause of that feeling, as for example when we speak of 'the feeling of a mosquito walking on the back of your neck'.

\footnotetext{
${ }^{2}$ Moore certain seems to endorse this conception of pleasure in his attack on hedonism in Chapter 3 of Principia Ethica. If I understand him correctly, he explicitly endorses the view earlier on p. 12 where he refers to 'a certain definite feeling called pleasure'.

${ }^{3}$ Presumably the view of Sidgwick and Brandt, among others.

${ }^{4} \mathrm{I}$ discussed this issue in a non-neutral way in my 'On the Intrinsic Value of Pleasures'.
} 
Such strictly sensory feelings are not to be confused with propositional attitudes. Perhaps when I step into the tub and feel the heat of the water, I also 'feel that the water is too hot'. But this latter 'feeling' is really just a belief (presumably based in some way on the fact that I am experiencing the actual feeling of heat as I step into the water). The 'that'-clause tips us off to this fact. The attitudinal feeling is different from the sensory feeling in some important ways. For one thing, there is a difference about truth. It makes just about no sense to say that a strict feeling is either true or false. Suppose I step into a tub of water and I get a feeling of hotness in my toe. Suppose the water is really not hot. Still, my feeling itself is not false. At most we can accuse it of being misleading. If in addition I have the propositional attitude misleadingly called 'the feeling that the water is hot,' but it isn't hot, then this attitude is more naturally said to be false. After all, it is just the false belief that the water is hot.

Another difference concerns phenomenological or apparent location. Whereas the sensory feeling of heat is located in my foot (and the feeling of pressure in the backrub case is located in my back and the feeling of the walking mosquito is located on my neck), it makes little sense to talk of the apparent location in my body of my feeling that the water is too hot. If it needs a location, I guess I would be happier just to say that it is located wherever I am. Genuine sensory feelings do not have propositional contents; they often do have locations. If there were sense data, feelings would be among them.

Some, as I have said, proceed as if pleasure were a sensory feeling, to be understood on the model of feelings of heat and cold, tickles and itches. We can call it 'sensory pleasure'. This sensory pleasure would be in some sense 'opposite' to a sort of sensory pain. Just as sensory pleasure is thought to be a feeling of some sort that we typically like, so sensory pain would be a feeling of some sort that we typically dislike. The 'oppositeness' of sensory pleasure and sensory pain would resemble the 'oppositeness' of sensory heat and cold, or sensory heaviness and sensory lightness.

While of course I acknowledge that there are things properly called 'feelings of pleasure', they are not central to my project here. I discuss them primarily to get them out of the way. The sorts of hedonism that fascinate me are not based on the idea that it is the presence of any such sensory feeling of pleasure that helps to enhance the quality of a person's life. My sorts of hedonism are based on the different idea that it is the presence of 'enjoyment' - not a feeling that makes a life better. Let's consider what enjoyment is.

2b. Enjoyment. Enjoyment is not a feeling. It is an attitude. Like so many other attitudes, it takes propositional entities (or states of affairs) as its objects. Thus, suppose I am reading an insightful and amusing philosophy paper. Suppose I find the paper to be enlightening and entertaining. In such a case, it makes sense to say that I am enjoying various facts about the paper. More ponderously, we might say that as I read the paper, I take attitudinal pleasure in the fact that the paper is so well written, or in the fact that it is filled with such interesting arguments and insights. Perhaps I take pleasure in the fact that the examples are so apt. To enjoy some state of affairs is to take attitudinal pleasure in this way in it.

Attitudinal pleasure is a mode of consciousness. It is a way of being aware of a state of affairs. It takes its place among such attitudes as hope and fear, belief and doubt, and 
recollection and anticipation. In order to take up any of these attitudes toward some state of affairs, one must be able to conceive that state of affairs. This is not to suggest that one must be able to express the state in words - even an inarticulate person can hope for a drink of water, or fear that there might be something under the bed. As I see it, it does not take tremendous intellectual sophistication to have such attitudes. By the wagging of her little tail, my dog Pippin indicates that she takes pleasure in the fact that we are about to take a ride in the truck.

Some features of enjoyment will play a role in the theories to be discussed. One of these is that enjoyments happen at times. Thus, it makes sense to say that I was enjoying the paper for a while, but eventually I came to some parts that were too complicated. Then I didn't enjoy it so much. Another feature of enjoyment is that it is a matter of degree: I might enjoy reading several of the term papers, but I might enjoy some of them more than others. For simplicity in exposition, we can assume that these intensities can be represented with numbers. Thus, we can say that at about 8:00pm I was enjoying to intensity +12 the reading of this paper, but that at about 10:30pm I was enjoying to intensity +2 the reading of this other paper. Papers read after midnight were not enjoyed at all.

Can we enjoy, or take pleasure in, a state of affairs that does not occur? Our ordinary ways of talking about enjoyment might suggest that this is impossible, but further reflection suggests that things are more complicated. Chisholm has provided a good example. $\bigsqcup_{\text {Suppose a }}$ candidate for office mistakenly thinks he won the election. Chisholm suggests that this candidate could be pleased about winning the election even though in fact he didn't win it. Here's another case that might seem even more convincing: suppose I mistakenly think that I will be meeting G. E. Moore soon. Suppose I am delighted about this. Clearly, I am pleased about something. It seems wrong to say that what I am pleased about is the fact that I think I will meet Moore. It seems better to say that I am pleased that I am going to meet him (even though I am not going to meet him). In what follows I will not assume that attitudinal pleasure is always directed toward truths. Perhaps the most we can say is that if you take pleasure in some state of affairs, then you must at least think that it's true.

Another aspect of the epistemology of enjoyment is puzzling, too. In an earlier era, philosophers sometimes said that such states as enjoyment are 'transparent' or 'self-revealing'. Some of them may have meant to suggest that if you are enjoying something, then you must know immediately that you are enjoying it. I have my doubts. I think we can deceive ourselves

\footnotetext{
${ }^{5}$ This is intended to be a comment on an objection raised by L. W. Sumner in his review of Utilitarianism, Hedonism, and Desert. Sumner claims there that my view goes wrong in part because it fails to accord any value to the lives of creatures such as dogs and cats. The failure, according to Sumner, depends upon the fact that such lowly creatures cannot have suitable propositional attitudes. He says that infants and many nonhuman animals 'lack the conceptual resources for understanding propositions' (p. 177) I agree that we must accommodate the fact that infants and nonhuman animals can take pleasure in things. I think my view does accommodate it. I think all sorts of lowly creatures have propositional attitudes all day long. I am sure Pippin has them. Thus, I reject Sumner's claim that infants and nonhuman animals lack the resources to have propositional attitudes.

${ }^{6}$ The intensity of enjoyment must not be confused with the 'strength' or 'intensity' of any feeling. One can take great pleasure in some state of affairs even though one does not experience any intense sensations while thinking about that state of affairs. Indeed, Stoicus (whose case is discussed below) might be very pleased that he is not feeling any intense feelings at all.

${ }^{7}$ In Brentano and Intrinsic Value, pp. 28-9.
} 
about our enjoyments. A person might think he is enjoying the taste and aroma of the wine when in fact he is really enjoying being seen in possession of a bottle with an impressive label.

Enjoyment has its opposite number. We might call this 'disenjoyment' but it is easier to call it attitudinal pain. Just as we say that someone takes pleasure in some things, we can say that he 'takes pain' in others. To take pain in something is to disenjoy it. If we represent amounts of enjoyment with numbers, then we can introduce a simplifying assumption: to disenjoy something to some extent, $n$, is to enjoy it to some negative extent, $-n$.

Some people are convinced that there is a deep conceptual link between the attitude of enjoyment and the feeling of sensory pleasure. For example, they may tell us that to enjoy something is to feel pleasure as a result of it (or as a result of thinking of it). I am convinced that this view is false $e^{8}$ but I will not debate it here. For present purposes it is sufficient that the distinction between attitudinal pleasure and sensory pleasure is clear. After a brief discussion of sensory hedonism, I will not be talking much about sensory pleasure. Most of the views to be discussed here concern attitudinal pleasure.

\section{The evaluation of lives}

There are many scales on which a life may be weighed. When we say that someone had a 'good life' we may be using 'good' to express extrinsic goodness. In such a case, we would be thinking (approximately) of evaluation in terms of 'overall benefit'. On this scale, the value of a life is largely a matter of the overall extent to which it contributes to human welfare. A Teresalike martyr who tends to the sick and needy might score well on this scale. And she might score fabulously well even if her own life is filled with unhappiness and pain. Clearly, this sort of evaluation presupposes some other sort of evaluation. If I want to know whether your life ranks high in terms of benefit to others, I need to know what would count as a benefit to others - I need to know what would make the lives of others rank high on some other scale. I am more interested here in this other scale.

Sometimes when we speak of a good life, we have in mind moral goodness. A life that is good in this way is one that is "morally good". Presumably, the martyr would get a high score on this scale as well. This reflects our sense that there is something morally good about helping others to live lives that rank high on some other scale. But again it is pretty clear that someone could live a life that is morally good even though she does not lead a life that is "good for her". Such a case might lead friends to wonder about cosmic injustice. 'She led such a good life; why couldn't things have turned out better for her?'

But my questions here concern neither extrinsic goodness nor moral goodness. I am interested in the value of a life for the one who lives it. Some like to say that this scale measures 'welfare'. Others would say it measures 'quality of life'. Aristotle seems to have this scale in mind when he wonders what makes a person 'happy', and seripusly considers the question

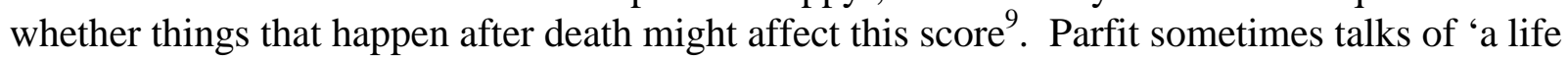

\footnotetext{
${ }^{8}$ And I presented a variety of arguments against it in 'Two Questions about Pleasure'.

${ }^{9}$ NE, Book I, Chapters 10-11.
} 
well worth living, I think he is alluding to this same scale of measurement. This is the sort of evaluation with which we will be concerned here.

When students and colleagues think back with affection on Chisholm and hope that his life went well for him, we are hoping that his life ranked high on this third scale. We are hoping that he led a life that was good for him. (Of course, some of us might also be concerned to know whether his life was good for others, and some might be curious about whether his life was morally good. However interesting such inquiries might be, they are not my topic here.)

From now on when I speak of 'the value of a person's life', I will be referring to that person's score on this third scale. Thus, I mean to be discussing the question whether the value of a person's life is determined by the extent to which he enjoys the things that happen to him in that life.

\section{A Simple form of Hedonism; Why it Fails}

Some people (especially critics) insist on understanding hedonism as a view about sensory pleasure and sensory pain. They insist that the hedonist must mean that the value of a life is determined by the total amount of sensory pleasure it contains, minus the total amount of sensory pain it contains. Views of this sort may be said to be forms of 'Sensory Hedonism'.

I am not interested in defending Sensory Hedonism. It is not my view. I reject it for a variety of reasons. For one thing, I reject it because it gives what I take to be the wrong evaluation of a life such as the life of Stoicus. According to the story, Stoicus just wants peace and quiet. He wants to live an unruffled life. We must be clear about Stoicus's desires: it's not that he wants peace and quiet because he thinks these will give him sensory pleasure. He wants peace and quiet as ends in themselves. In fact, he prefers not to have sensory pleasure. He prefers not to have sensory pleasure in part because he fears that if he had some sensory pleasure, it would ruffle his life. He feels the same way about sensory pain: he does not want it.

Suppose Stoicus gets exactly what he wants -- peace, quiet, no sensory pleasure, and no sensory pain. Suppose that as he receives his daily dose of peace and quiet, Stoicus is pleased. That is, suppose he enjoys the peace and quiet. Suppose he takes attitudinal pleasure in various facts about his life, including the fact that he is not experiencing any sensory pleasure. Suppose Stoicus eventually dies a happy man. He lived 90 years of somewhat boring but on the whole quite enjoyable peace and quiet. Stoicus thinks (right before he dies) that his has been an outstandingly good life.

Sensory Hedonism implies that Stoicus did not have a good life. This follows from the fact that the life of Stoicus did not contain any episodes of sensory pleasure. But if Stoicus was happy with his life, and enjoyed the experiences that came his way, and got precisely what he wanted at every moment, it seems strange to say that there was nothing good about his life. Although it is not the sort of life I would like to lead, I must confess that it seems quite a nice life

\footnotetext{
${ }^{10}$ Reasons and Persons, passim. For an especially insightful discussion of various views on these topics, see Parfit's Appendix I, 'What Makes Someone's Life Go Best'. Pp. 493-502.
} 
for someone with Stoicus's tastes. Dull perhaps, but at the same time pleasant enough (in its non-sensory way).

I mention the example of Stoicus for several reasons. For one, it is supposed to show that Sensory Hedonism is false. It does this by showing that it is possible for a person to have quite a good life (as measured on the third scale) even though he experiences no sensory pleasure. Another reason to mention the life of Stoicus is that it is supposed to drive home the difference between sensory pleasure and attitudinal pleasure. Stoicus had none of the former, but plenty of the latter. And the third reason to mention Stoicus is that reflection on his case may highlight the plausibility of attitudinal hedonism. 12

Attitudinal hedonism is the view that what makes a life good for the one who lives it is that it contains a lot of enjoyment, or attitudinal pleasure, and relatively little disenjoyment, or attitudinal pain. I now turn to a discussion this sort of view.

\section{Attitudinal Hedonism}

One form of attitudinal hedonism can be constructed as follows: first we assume that whenever a person takes attitudinal pleasure in any state of affairs, he does so for some period of time and at some average intensity. Of course, in real-life cases it may be difficult or even impossible to determine the intensity of a person's pleasure, and there may be some difficulty in determining precisely when the pleasure begins and when it ends. But I will assume that such problems are not deeply conceptual - they are merely practical difficulties. Thus, I assume that whenever a person is pleased about something, there is some amount of attitudinal pleasure he takes in this something. Let's assume at the outset that this amount is determined by the intensity and duration of his pleasure.

I make similar assumptions about attitudinal pain.

Let us imagine a numerical scale on which these attitudinal pleasures can be measured. Assume that the scale assigns positive numbers to pleasures, with higher number representing more intense and longer lasting pleasures. Assume that it assigns negative numbers, with lower (absolutely greater) negative numbers representing more intense and longer lasting pains.

\footnotetext{
${ }^{11}$ I think the life of Stoicus may be the sort of life that the hedonist Epicurus extolled. He notoriously defended the view that 'pleasure is the absence of pain' - clearly a view not to be taken too literally. Perhaps he meant to say that the most pleasant sort of life is one not troubled by pain or sensory pleasure. In his 'Letter to Menoeceus' he says, 'When we maintain that pleasure is the end, we do not mean the pleasures of profligates and those that consist in sensuality, as is supposed by some who are either ignorant or disagree with us or do not understand, but freedom from pain in the body and from trouble in the mind.'

${ }^{12}$ It might appear that the real moral of the story of Stoicus is that we should consider some form of satisfactionism - the idea that what makes a life worth living is that it is filled with satisfied desires. I am convinced that this sort of view is indefensible. This is not the place to present arguments. For an impressive critical discussion, see Section 1 of Chapter 3 of Adams' Finite and Infinite Goods.
} 
We might suppose that the value of a person's life according to attitudinal hedonism would be the sum, for all the attitudinal pleasures and pains that person ever experiences in that life, of these numbers. Alas, things are not quite so simple.

We must recognize basic attitudinal pleasures and pains. Otherwise, we will run into some nagging problems about double-counting. 13 To see this in a concrete case, imagine that Stoicus is pleased to degree +10 that there is fresh water in the pitcher. Imagine further that he is pleased that there is fresh water because he realizes that he will be able to drink it, and he is pleased to degree +10 that he will be able to drink it. Still further, imagine that he is pleased that he will be able to drink it because he realizes that if he drinks it, he will not be thirsty, and he will be pleased to degree +10 to avoid thirst. Finally, imagine that he is pleased that he will avoid thirst because he believes that thirst would be unpleasant.

I think it would be wrong to give Stoicus a score of +40 in such a case. To do so would be to give extra credit merely for having longer chains of belief. I cannot see that having such extra-long chains makes a person's life any better. I propose instead to count only the pleasures at the ends of the chains. Thus, in the present case, Stoicus should get only 10 points for his water-in-the pitcher/drinking-it/avoiding thirst pleasure.

Thus, I propose that we say that $S$ is intrinsically attitudinally pleased to degree $n$ about $p$ at $t$ if $\mathrm{S}$ is attitudinally pleased to degree $\mathrm{n}$ about $\mathrm{p}$ at $\mathrm{t}$, but not in virtue of the fact that he is attitudinally pleased about something else at $t$. Intrinsic pleasure is pleasure taken in a thing 'for its own sake'. I assume that there is also intrinsic attitudinal displeasure.

Another sort of double-counting must be avoided, too. Consider the case in which Stoicus is intrinsically pleased about three things at once: that he feels no thirst, that he feels no sensory pain, and that he feels no sensory pleasure. Suppose he takes exactly 10 units of attitudinal pleasure in each of these states. But he also takes pleasure in the various conjunctions and disjunctions of these states. For example, he takes pleasure (perhaps 20 units of it) in the fact that he feels neither sensory pleasure nor sensory pain. Surely we would be guilty of an overcount if we added all these 20's and 30's to the score already assigned to Stoicus.

Let us assume that whenever a person takes pleasure in some complex state of affairs such as the conjunctions just illustrated, that he takes this pleasure in virtue of the fact that he takes pleasure in the simpler components of which these are composed. Thus, there is a noncausal way in which you can take pleasure in $\mathrm{p}$ in virtue of the fact that you take pleasure in $\mathrm{q}$. Let us understand 'in virtue of' in this broader way, so that the proposed account of intrinsic attitudinal pleasure is sensitive to both ways of being intrinsic.

For purposes of discussion, then, let us understand Intrinsic Attitudinal Hedonism (IAH) to be the view that the value of a person's life is determined by the total amount of intrinsic attitudinal pleasure the person enjoys during that life (counting intrinsic attitudinal pain as 'negative pleasure'). This theory implies that someone like Stoicus leads a pretty good life. That's because Stoicus was described as enjoying his peace and quiet and his lack of sensory pain and pleasure, and as not disenjoying anything. I assume that these enjoyments are either

\footnotetext{
${ }^{13}$ For further discussion, see my 'Basic Intrinsic Value'.
} 
themselves intrinsic, or depend upon some other intrinsic enjoyments lying deeper in the psyche of Stoicus. So Stoicus gets quite a few positive points, and no negative points. His life is good, just as he declared it to be.

It's interesting to see what IAH implies about the life of a garden-variety sensory hedonist. Suppose Hugh enjoys sex, drugs, and rock 'n' roll. Suppose he has many delightful sensory experiences. He takes great intrinsic attitudinal pleasure in the various states of affairs consisting of his feeling this sensory pleasure, or his feeling that sensory pleasure. As a result of the sheerest good fortune, Hugh never suffers much pain beyond the occasional hangover, or mild bout of indigestion. IAH implies that Hugh's life was excellent. ${ }^{14}$ This seems reasonable to me. Furthermore, it is the sort of thing some sensory hedonists would want to say. And IAH yields precisely this result.

It's interesting to note that IAH does not imply that the goodness of Hugh's life is ultimately determined by the fact that he experienced a lot of sensory pleasures. (That would be the basis on which typical forms of Sensory Hedonism would evaluate his life.) Rather, IAH bases its judgment upon the fact that Hugh took intrinsic attitudinal pleasure in the fact that he was having these experiences. If another person (Stoicus perhaps) were forced to endure precisely these experiences, but didn't enjoy them, IAH would declare (correctly in my view) that his life was worthless. And IAH would reach this conclusion in spite of the fact that the sensory experiences were sense-datum for sense-datum indiscernible from those enjoyed by Hugh.

\section{Some Classic Objections to Hedonism}

I hope at this point that the general outlines of attitudinal hedonism are clear enough to permit critical discussion. I now turn to consideration of some classic objections to hedonism. It is not clear that the philosophers who presented these objections intended to be attacking a view precisely like IAH. But I will take the liberty of interpreting these objections as objections to the view I have sketched. Perhaps this will serve to make attitudinal hedonism clearer. It will also eventually lead me to introduce some alternatives to the theory.

6a. Shelly Kagap discusses one of the most common and forceful objections to hedonism in his 'Me and My Life' 15 . According to Kagan, hedonism implies that what determines the quality of a person's life is something completely internal to the person - in this case a certain

\footnotetext{
${ }^{14}$ Excellent on the third scale. This sort of hedonism makes no evaluation of Hugh's life on any other scale. So it is consistent with what I have said to say in addition that Hugh's life ranks low in terms of value to others as well as in terms of moral value. Discussions with Owen McLeod have convinced me that there might be yet a fourth scale on which a life may be evaluated. Perhaps the sense that there is something amiss in Hugh's life comes from the fact that his pleasures were somehow degrading, or less than fully 'admirable'. Maybe sometimes when we evaluate a life, we are thinking of the extent to which that life is admirable in this way - a life that would serve as a good example for our children. In the present context, however, I am trying to focus on the question whether Hugh's life is good for Hugh. In other words, I am evaluating it on the third scale.

15 Proceedings of the Aristotelian Society (1984): 309-324. Kagan repeats these arguments on pp. 34-6 of his Normative Ethics. Similar objections to hedonism can be found in many places. Adams, for example, makes essentially the same point on p. 84 of his Finite and Infinite Goods.
} 
mental state. Kagan thus says that hedonism is a form of 'mental statism'. Hedonism, like all forms of mental statism, implies that if two lives are alike with respect to mental states, they must also be alike with respect to value. In particular, hedonism implies that if two lives are alike with respect to pleasures and pains, then those lives are of equal value. This remains true even if one of the individuals takes his pleasures from correctly perceived interactions with real human beings, and the other individual is a mere brain in a vat, utterly unconnected with other people but taking himself to be living a life like the first person's. Kagan thinks that this is a source of trouble for hedonism.

Rather than letting the issue turn on far-fetched cases involving brains in vats, Kagan, following Tom Nagel, considers the fairly realistic case of a happy businessman. The businessman is happy because, as he thinks, his career is going well, he is respected in his community, and he has a loving family. In the example, all of his assumptions are false. The businessman is in fact held in utter contempt by his colleagues, deeply deceived by his adulterous wife, and hated by his children. Each has his or her reasons for engaging in the deception, but the result is the same: the businessman's happiness is completely dependent upon his widespread misapprehension of his circumstances. If he knew the truth about his colleagues, his wife, and his children, he would be miserable. Kagan concludes the discussion of this example by saying, 'In thinking about this man's life, it is difficult to believe that it is all a life could be, that this life has gone about as well as a life could go. Yet this seems to be the very conclusion mental state theories must reach. ... So mental state theories must be wrong. 16

Since we are considering a form of attitudinal hedonism, let us be sure to understand the case appropriately for present purposes. Let us stipulate that the businessman takes immediate attitudinal pleasure in many states of affairs, taking them all to be true. But they are all false. So, for example, this businessman is intrinsically pleased that he is respected by his colleagues, but in fact he is not respected by his colleagues. He is intrinsically pleased that he his loved by children, but in fact he is not loved by his children, and so on.

The objection should be clear. Attitudinal hedonism implies that the businessman's life is a good one, yet none of us would want such a life; none of us would wish such a life for our loved ones; such a life is not easily thought to be ideal.

Variants of this objection haye been presented by a number of anti-hedonists and some of them may seem pretty persuasive. 17 Nevertheless, the attitudinal hedonist need not be utterly crushed. Some such hedonists might reply by saying that the life of the deceived businessman is not so bad after all. Perhaps we can explain away our sense that something is amiss in the businessman's life by pointing out that we would not like to be deceived, and we would be pained to learn that our colleagues and family have been holding us in contempt for all these years. This helps to explain the fact that none of us would voluntarily choose the life of the deceived businessman. We know things about his life that he does not know. Since we know these things, we would not enjoy the experiences he enjoys. Hence, his life seems unattractive to us

16 Normative Ethics, 35.

17 Robert Nozick's example of the 'experience machine' comes to mind here. See his Anarchy, State, and Utopia, pp. 42-5. 
Furthermore, if any of his deceivers should slip up, the businessman might discover his real situation. Then he would be miserable. We would not like to have a life constantly on the brink of misery. However, in the case as described, it is stipulated that he does not discover his real situation, and is not miserable. If we were to ask him how his life is going, he would surely insist that he is living a fine life. Some would say that since the businessman does not know about the deception, it does not hurt him. Hence, it is not entirely clear that hedonism's implications are indefensible. Perhaps considerations such as these help to explain away our intuitive sense that his life is not all a life could be.

But the defender of Attitudinal Hedonism does not have to take this "bite the bullet" line. He can move to higher ground. He can slightly revise the axiology. As before, he can say that the fundamental goods are takings of intrinsic pleasure in various states of affairs, but he can modify this by saying that such takings of pleasures enhance the value of a life more when they are takings of pleasures in true states of affairs. This single modification yields a view according to which the life of the deceived businessman is not very good, even if internally indiscernible from the life of his cousin the undeceived businessman whose mental life is just the same, but whose family and colleagues are in reality as they appear to him to be.

It's not clear that the revised axiology is a form of mental statism, since it implies that it's possible for there to be two lives exactly alike ("from the inside") with respect to mental states, but unlike in value. But on the other hand, it's interesting to note that even the revised theory makes the value of a life depend on mental states - enjoyments after all are mental states -- it's just that the question how much a certain state counts depends in part upon whether the object of that state is true. So I don't know whether Kagan would categorize this as a form of mental statism or not. Since the view itself is fairly clear, I see no reason to worry about whether it is a form of mental statism. In any case, it is clearly a form of hedonism. Let us call the revised theory 'Veridical Intrinsic Attitudinal Hedonism', or 'VIAH'.

My point here is to show that attitudinal hedonism has the resources to deal with the example of the deceived businessman. If you think that the deceived businessman's life is less valuable than the life of his undeceived internal duplicate, then I offer VIAH for you. If you think that the twin businessmen lead lives of equal value -- that where pleasure is concerned, truth does not matter -- then I offer IAH for you. Either way, there should be some form of hedonism that will yield results consistent with your axiological intuitions about these cases.

6b. The Argument from Worthless Pleasures. A number of philosophers have claimed that certain kinds of pleasure are not good, and do not serve to enhance the value of any life. They have appealed to such pleasures in their attacks on hedonism.

Aristotle hints at this in the Nicomachean Ethics (X.3) where he speaks of 'disgraceful' and 'base' pleasures. Broad makes the case quite persuasively in Five Types of Ethical Theory. He more or less defines malice in such a way that a person enjoys malicious pleasure iff s/he takes pleasure in some other person's suffering. 18 Brandt makes a similar point in his argument against hedonism in Ethical Theory. He describes some women who attended beheadings in

\footnotetext{
${ }^{18}$ Broad, Five Types of Ethical Theory, pp. 53-4 in the excerpt included in Brandt's Value and Obligation.
} 


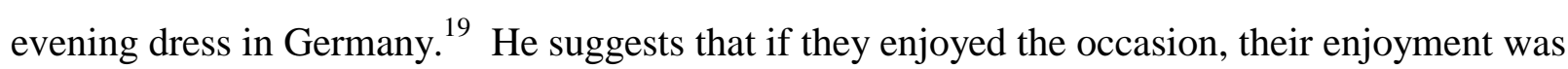
not intrinsically desirable. Moore does not (so far as I know) make explicit use of precisely this argument, but he apparently accepts the main premise. He speaks of eruelty, and he says that one essential component of it is the enjoyment of pain in other people ${ }^{20}$. He says that cruelty is a great mixed evil, containing a good part (enjoyment, which is a sort of pleasure) and a bad part (the pain of the other person). The whole thus formed is judged to be intrinsically bad. Brentano makes a similar claim, although his discussion is open to various interpretations.

In ‘Two Unique Cases of Preferability’, Brentano says:

'What of pleasure in the bad? Is it itself something that is good? Aristotle says that it is not. ... The hedonists expressed the contrary view,... But their view is to be rejected. ... Pleasure in the bad is, as pleasure, something that is good, but at the same time, as an incorrect emotion, it is something that is bad.

I will attempt to formulate the argument clearly, so that useful discussion may ensue. And as I formulate, I will try to construe the argument in such a way as to make it directly relevant to the forms of intrinsic attitudinal hedonism I have introduced. Thus, I will not be speaking of 'feelings of pleasure'. I will be speaking of attitudinal pleasures whose objects are bad, or unworthy of pleasurable contemplation.

Suppose some terrorist really hates children. Suppose he sets off a bomb at a playground, and then watches the news on TV. When he sees the suffering children choking and gasping and bleeding, and learns of the many injuries and deaths, this terrorist is delighted. He takes pleasure in the misery of his victims. More precisely, he takes veridical intrinsic attitudinal pleasure of a high degree in the fact that the innocent children are suffering.

Suppose the terrorist does this many times over, and each time thoroughly enjoys the fruits of his labor. Suppose at the same time that his life is not filled with counterbalancing pains. If VIAH were true, the life of this terrorist would be a good one. We would have to agree that things turned out well for him, and the quality of his life was high. Many of us, I suspect, would be inclined to reject this evaluation, and with it attitudinal hedonism. The problem here is that while the life of the terrorist was filled with large doses of veridical intrinsic attitudinal pleasure, these pleasures were the pleasures of cruelty. Pleasures such as these might seem to make a life worse, rather than better. 22

Other philosophers have reminded us of other worthless pleasures. In a memorable passage, Moore says: 'It is commonly held that certain of what would be called the lowest forms of sexual enjoyment' might be 'the most pleasant states we ever experience. 3 And in this

\footnotetext{
${ }^{19}$ Brandt, Ethical Theory, p. 316.

${ }^{20}$ Moore, Principia Ethica Chapter VI, Section 125.

${ }^{21}$ OKRW, p. 90

${ }^{22}$ It is important, in considering a case such as this, to be sure to keep in mind the fact that we are talking about evaluation on the third scale. We are not asking whether the terrorist led a morally good life, or whether he led a life that was good for others. Nor are we asking whether his pleasures were 'admirable'. We are asking whether he led a life that was 'good for him'. Though his pleasures were directed toward wholly inappropriate objects, one could still insist that if he enjoyed these things, his life was good for him. Many antihedonists prefer not to say this. ${ }^{23}$ Moore, Principia Ethica Chapter III, Section 56.
} 
context he speaks of 'a perpetual indulgence in bestiality'. He says (roughly) that if hedonism were true, then this perpetual indulgence in bestiality would be 'heaven indeed, and all human endeavors should be devoted to its realisation. I venture to think (says Moore) that this view is as false as it is paradoxical'.

Let us try to visualize the life to which Moore here alludes, adjusted so as to be directly relevant to VIAH. Imagine a person -- we can call him 'Porky' -- who spends all his time in the pigsty, engaging in the most obscene sexual activities imaginable. I stipulate that Porky takes great intrinsic attitudinal pleasure in these activities and the feelings they stimulate. In the example, he really does engage in the activities and feel the feelings. Thus, his pleasures are veridical, too. Let's imagine that Porky happily carries on like this for many years. Imagine also that Porky has no human friends; has no other sources of pleasure; has no interesting knowledge.

Moore's point (as modified to apply here) is that VIAH implies that Porky's life is one of the best we can imagine - 'heaven indeed'. Yet, as Moore indicates, that implication is a bit hard to swallow.

Objectors claim that Porky's life is not very good in spite of the stipulated fact that it contains a lot of veridical intrinsic attitudinal pleasure. This example is thought to illustrate a second way in which pleasure can be worthless. As Aristotle said, base pleasures do not enhance the value of a life.

\section{A More Complex form of Hedonism}

I think it is possible to modify our attitudinal hedonism so as to make it generate the desired results in these cases, too. Moore, Brentano, and Chisholm have pointed the way. Roughly, the idea is to say that the intrinsic value of an attitudinal pleasure is determined not simply by the intensity and duration and truthfulness of that pleasure, but by these in combination with the appropriateness of the object of that pleasure. (Similarly for attitudinal pains.) More exactly, the value of a pleasure is enhanced when it is pleasure taken in a worthy object, such as something good, or beautiful. The value of a pleasure is mitigated when it is pleasure taken in an unworthy object, such as something evil, or ugly. The disvalue of a pain is mitigated (made less bad) when it is pain taken in an object worthy of pain, such as something

\footnotetext{
${ }^{24}$ On pp. 146-7 of Ethics, Moore presents a closely related argument against hedonism. He discusses the idea that 'one whole will be intrinsically better than another, whenever and only when it contains more pleasure, no matter what they may be like in other respects.' He goes on to say that this view (intended to be a form of hedonism) 'involves our saying that ... the state of mind of a drunkard, when he is intensely pleased with breaking crockery, is just as valuable, in itself -- just as well worth having, as that of a man who is fully realizing all that is exquisite in the tragedy of King Lear, provided only the mere quantity of pleasure in both cases is the same.' He acknowledges that there is no way of proving that this implication is false; but he thinks it self evident that anyone who accepts this implication is making a mistake. My reaction to this argument is relevantly similar to my reaction to the Porky argument.

${ }^{25}$ Similar considerations would apply in the case of 'good pains' such as pain taken in the suffering of innocents. Time and space constraints do not permit discussion of these issues here.
} 
evil, or ugly. The value of a pain is enhanced (made yet worse) when it is pain taken in an object unworthy of this attitude, such as something good or beautiful. 26

I think it's reasonable to describe certain objects by saying that they 'deserve to be objects of pleasure'. In the case of such objects it is fitting, or appropriate, that someone take pleasure in them. Thus, for example, if an object is genuinely beautiful, then it deserves to be appreciated. If an object is good, then it deserves to be admired. So we can identify the objects worthy of pleasure as those that deserve to have pleasure taken in them. (And similarly for pain and its objects.) In this way we make essential use of the concept of desert in the formulation of our hedonistic axiology.

While we are making this adjustment for pleasure-worthiness, we might as well incorporate the adjustment for truth. That is, we can view the veridicalness of the object of a pleasure as yet another factor that enhances its worthiness of pleasure. We therefore can say that when someone takes pleasure in a true state of affairs, his pleasure is more valuable, other things being equal, than it would have been if the object of his pleasure had been false.

One version of the resulting theory may be called 'Desert Adjusted Intrinsic Attitudinal Hedonism' (or DAIAH). It is structurally similar to views discussed by Moore, Brentano, Chisholm, Hurka, Lemos, Adams and others 27 . It is intended to generate the desired results in the cases involving malicious and base pleasures. Since the objects of those pleasures are respectively evil and disgusting, DAIAH declares the pleasures to be much less valuable. 8 If the life of the terrorist is filled with pleasures of this first worthless sort, and the life of Porky is filled with pleasures of the second worthless sort, then DAIAH declares those lives to be of little value. ${ }^{29}$ I claim - though I cannot take the time to show it in detail here - that the view also deals adequately with what we may dub 'worthwhile pains', such as intrinsic attitudinal pain taken in evil or ugly objects.

\section{Yet Another Objection}

I like DAIAH. I think I know some of its implications, and I am happy to accept them. I think I am in a state approaching reflective equilibrium while believing it. However, my point here is not to show that DAIAH is the one true form of hedonism. Rather, my point is merely to

\footnotetext{
${ }^{26}$ I speak loosely here. I do not mean to suggest that pleasures have variable intrinsic values -- values that can be increased or decreased depending upon changes in the nature of their objects. Rather, what I mean is that the fundamental bearers of intrinsic value should be taken to be complex states of affairs involving not only the intensity and duration and truthfulness of a pleasure, but something also about the worthiness of its object - the extent to which that object deserves to be enjoyed. Thus, a basic value state, on this axiology, would be something of this form: S takes intrinsic attitudinal pleasure of intensity $n 1$ and duration $m 1$ in state of affairs $P$, while $P$ is worthy of pleasure of intensity $n 2$ and duration $m 2 .$.

${ }^{27}$ Moore endorses something like this in Chapter VI of Principia Ethica. Brentano did it in OKRW. Chisholm does it in Chapter 5 of Brentano and Intrinsic Value. Hurka does it in 'Virtue as Loving the Good'. Lemos does it in Intrinsic Value: Concept and Warrant.. Adams does it in Finite and Infinite Goods. Michael Zimmerman does it in his 'On the Intrinsic Value of States of Pleasure'.

${ }^{28}$ An extreme form of DAIAH would declare some such pleasures to be bad. This is the transvaluation case. I am neutral here on transvaluation.

${ }^{29} \mathrm{Or}$, if we transvaluate, to be of negative value.
} 
show that it is possible to formulate a kind of hedonism that is immune to the objections presented by Aristotle, Broad, Moore and the others based on the possibility of misdirected pleasure. We can be hedonists without saying that base and malicious pleasures improve a life as much as pleasures taken in worthier objects.

Yet a further classic objection to hedonism remains. A number of anti-hedonists have made use of this argument, and I make no claims about priority. I cite the version to be found in Ross mainly because I think it is a neat and persuasive formulation of the argument.

\title{
Ross says:
}

\begin{abstract}
If we compare two imaginary states of the universe, alike in the total amounts of virtue and vice and of pleasure and pain present in the two, but in one of which the virtuous were all happy and the vicious miserable, while in the other the virtuous were miserable and the vicious happy, very few people would hesitate to say that the first was a much better state of the universe than the second. It would seem then that, besides virtue and pleasure, we must recognize, as a thirdindependent good, the apportionment of pleasure and pain to the virtuous and the vicious respectively.
\end{abstract}

Although Ross says it quite well himself, I'd like to say it again in my own words to insure that the objection bears directly on the forms of attitudinal hedonism under consideration here. I think Ross wants us to imagine two possible worlds. The worlds are supposed to be exactly alike with respect to several important features - virtue and vice, pleasure and pain. So let us stipulate that each world contains a million virtuous people and million vicious people, and let us stipulate that each world contains a million people who enjoy lives filled with objectappropriate intrinsic attitudinal pleasure, and each world also contains a million people who live lives filled with object inappropriate intrinsic attitudinal pain. So the worlds are very similar. The central difference concerns who gets what. In W1, the virtuous people get to live the lives filled with object appropriate pleasure and the vicious people get to live the lives filled with pain. It's the reverse in W2. There 'bad things happen to good people' and 'good things happen to bad people'.

I want to be clear about what goes on in W2. Imagine a life filled with pleasures taken in appropriate objects. Here the pleasure-seeker is no Porky or perverted terrorist. This is an educated, tasteful aesthete. He takes deep pleasure in such things as genuinely beautiful works of art, and the innocent frolicking of healthy, happy children. The only problem is that this aesthete is also a thief who has stolen the art from those to whom it rightly belongs, and a kidnapper who has kidnapped the frolicking children. So while the objects deserve to be enjoyed, this thief and kidnapper does not deserve to be enjoying them.

The crucial thing to note about these worlds is that they are exactly alike with respect to veridical intrinsic attitudinal pleasures and pains. Ross's point (modified to apply to the theory currently under consideration) is that DAIAH implies that these worlds are equally valuable. Yet Ross thinks (and I think too) that the just world, W1, is much better than the equally pleasant but unjust world, W2. This might seem to refute DAIAH.

\footnotetext{
${ }^{30}$ From The Right and the Good, quoted in Brandt's Value and Obligation, p. 123
} 
Ross's example is interesting and insightful. It draws our attention to an important consideration. Nevertheless, I think it does not refute DAIAH. Note that DAIAH as so far stated says nothing about values of worlds. It speaks only about the values of lives. Yet Ross's argument is not based on any alleged misevaluation of lives. He did not say that the lives of the happy vicious people were misevaluated by hedonism. Indeed, it seems to me that DAIAH might get this right. Rather, Ross's claim concerns the evaluation of worlds. Since DAIAH gives no evaluation of worlds, it cannot be guilty of giving the wrong evaluation of the worlds described by Ross.

If we add a certain assumption to DAIAH, we will get the conclusion Ross attacks. The assumption is that the value of a world is equal to the sum of the values of the lives lived there. Since DAIAH gives equivalent evaluations of the lives in W1 and W2, it would then yield the conclusion that W1 is equal in value to W2. Ross could then launch his attack. But perhaps the defender of DAIAH would not endorse this aggregative principle. Perhaps he would acknowledge that a world could be filled with good lives, and yet be a bad world because the wrong people get to live those good lives. Then Ross's argument would lose its target.

It seems to me that an axiological theory should give an account of what makes a life worth living. DAIAH does this. It tells us that the value of a life is determined by the net extent to which the liver of that life experiences object appropriate veridical intrinsic attitudinal

pleasures. Ross's example does not raise any serious trouble for DAIAH on these grounds. But an axiological theory should also give an account of what makes a world worth creating, or aiming for. If we jettison the idea that the value of a world is the sum of the values of the lives lived there, then DAIAH says nothing about this question. We should address this issue.

\section{Double Desert Adjusted Hedonism}

We have adjusted the value of a pleasure to reflect the extent to which the object of that pleasure deserves to be enjoyed. This (I claim) solves the problem of worthless pleasures (and worthwhile pains) and gives the proper basis for the evaluation of lives. I propose that we adjust this value again, this time to reflect the extent to which the subject - the one who experiences the pleasure -- deserves to be experiencing it. This 'double desert adjustment' will give the proper basis for the evaluation of worlds and will solve the problem set by Ross.

Suppose a person takes intrinsic attitudinal pleasure in some object. To find the double desert adjusted value of his pleasure, we need to take several steps. First, we need to determine the intensity and duration and truthfulness of the pleasure. Other things being equal, longer and stronger and true pleasures are more valuable. Next we need to determine the extent to which the object of the pleasure deserves to be enjoyed. We ask if the object is a worthy object of pleasure. Other things being equal, pleasure taken in more worthy objects is more valuable. (This is the first adjustment in value for desert, taken to insure that the object of the pleasure deserves to be enjoyed.) Then finally we need to determine the extent to which the subject of the pleasure deserves to be taking that particular pleasure. Other things being equal, pleasures enjoyed by more deserving subjects are more valuable than otherwise similar pleasures enjoyed 
by less deserving subjects. This is the second adjustment in value for desert, taken to insure that the subject of the pleasure deserves to be enjoying it. 11

Similar adjustments in value would be made to episodes of intrinsic attitudinal pain. Roughly, the idea here would be that when a person who fully deserves to be taking pain in a certain object does take pain in that object, then the badness of his pain is mitigated. Other things being equal, such pains are less bad for the world than similar pains suffered by people who do not deserve to be undergoing them. Pains suffered by people who deserve not to be suffering them are worse, other things being equal, than similar pains suffered by people who do deserve to be suffering them. As a result of all this, we can see that the worst pains (on this double-adjusted scale) are intense, long-lasting pains taken in objects that deserve not to be objects of pain, suffered by people who deserve not to be suffering them.

Considerations of space and time do not permit me to give a full account of the nature, sources, and structure of desert. (I have discussed these issues elsewhere, and hope to say more in the future.) Such things as excessive or deficient prior receipt, legal or moral 'rights' to pleasure, hard work, virtue and vice, etc. probably influence the extent to which someone deserves some pleasure. I recognize that more needs to be said, but this is not the place to say it.

The resulting value may be called the Double Desert Adjusted Value of the pleasure. Similar procedures would yield the DDAV of any intrinsic attitudinal pains. Double Desert Adjusted Intrinsic Attitudinal Hedonism (DDAIAH) is the view that the value of a world (or outcome, or other complex state of affairs) is the sum of the Double Desert Adjusted Values of the intrinsic attitudinal pleasures enjoyed and pains suffered in that world (or outcome, or whatever). My answer to Ross is this: 'Yes, Ross, you have presented a problem for an extension of DAIAH. You have shown that we would go wrong if we evaluated worlds strictly in terms of single desert-adjusted intrinsic attitudinal pleasures and pains. But we are not forced to endorse that extension. Instead, we can endorse DDAIAH.'

My view as a whole is roughly this:

1. The fundamental bearers of value are complex states of affairs of this form: $S$ takes intrinsic attitudinal pleasure (pain) of intensity $n$ and duration $m$ in object $P$ at time $t$, when $S$ deserves to degree $r$ to be taking that pleasure (pain) and $P$ deserves to degree s to be the object of that pleasure (pain).

2. The desert adjusted value of such a state is a function of intensity, duration, truth, and pleasure (pain) worthiness of its object.

3. The double desert adjusted value of such a state is a function of intensity, duration, truth, pleasure (pain) worthiness of its object, and the pleasure (pain) worthiness of its subject.

\footnotetext{
${ }^{31}$ Another caveat: strictly, my view is that the basic intrinsic value states need to be sufficiently complicated so as to indicate the intensity, duration, truth-value, and pleasure-worthiness of the object of the pleasure, as well as the pleasure-worthiness of the subject of the pleasure. Each such basic intrinsic value state will have a fixed intrinsic value. Talk of 'enhancement' and 'mitigation' is merely heuristic.
} 
4. The value (on the third scale) of a life is the sum of the desert adjusted values of the fundamental intrinsic attitudinal pleasure (pain) states in that life.

5. The value (on the third scale) of a world is the sum of the double desert adjusted values of the fundamental intrinsic attitudinal pleasure (pain) states in that world.

\section{Concluding Comment; Puzzles Yet to be Solved}

I mentioned earlier that there would be some loose ends. There are. Let me briefly mention some of them.

a. Infinite worlds and lives. I like totalism. That is, I like the idea that the value of a complex thing such as a world or a life is the sum of the values of certain selected items within the life or world. Totalism makes it possible to engage in axiology. If we were 'world holists' maintaining that the value of a world is an emergent property, not functionally dependent upon the values of the fundamental value-bearers within, then it would be hard to explain why any world has its value. At best we could struggle to describe a really good world, and then hint that the value of other worlds is to be assessed in some purely intuitive way by appeal to the extent to which it resembles the ideal world. That would be unfortunate.

But totalism breaks down in the case of worlds or lives containing infinite supplies of fundamental value bearers. The sums do not come out. I do not know how to set this right.

b. Repugnant conclusion. Totalism also runs into trouble in cases involving huge (but finite) supplies of small pleasures. No matter how good a world full of intense, long-lasting, well-directed, well-deserved pleasures might be, we can always imagine another world full of an enormops number of barely noticeable pleasures. Totalism implies that the latter would is better. Parfit ${ }^{2}$ has drawn attention to the repugnancy of this conclusion. Although I have suggested a solution elsewhere, I have to admit that I do not know how to set this right.

c. Origins, bases, etc. of desert. The view sketched here makes essential use of the concept of desert. This appears first in the notion of the pleasure (pain) worthy object. I said that such objects 'deserve to be objects of pleasure (pain)'. It appears again in the concept of the pleasure (pain) worthy subject. I said that such subjects deserve to experience pleasure (pain). To spell out the theory in its full glory, one would need to explain in detail what makes an object deserve to be an object of pleasure (pain). One would also need to explain in detail what makes a person deserve to be a subject of pleasure. I have not completed either of these jobs (but I have said some words about them elsewhere). ${ }^{{ }_{3}}$ Thus, I acknowledge that the present work is incomplete. I hope someday to get closer to completion.

d. Epistemology. Finally, the skeptical reader may wonder what makes me think I know so much about these things. He may question my epistemic credentials. What authorizes me to pontificate as I have? At present, I prefer not to answer this question. Perhaps I have moral

\footnotetext{
${ }^{32}$ Perhaps following McTaggart.

${ }^{33}$ See Section 4 of 'Adjusting Utility for Justice'.
} 
intuition. Perhaps I am just emoting. Perhaps I find myself in reflective equilibrium with these thoughts.

I am inclined to believe that Professor Chisholm was a fundamentally decent man. In my dealings with him, it always seemed to me that he was devoted to the truth, and concerned about treating others with respect. Of course, I didn't know Chisholm intimately. Maybe he had some terrible vice that was hidden from me. But I doubt it. As a result, it seems to me that Chisholm was the sort of man who deserves to live a happy life.

Furthermore, it seems to me that the objects of Chisholm's pleasures were uniformly pleasure-worthy states. He took pleasure in seeking knowledge of important things and conveying that knowledge to his students; he took pleasure in the welfare of his friends, family, and students. He took pleasure in the beauty of the sea and of trains. Each of these is an object that deserves to have pleasure taken in it.

I know that there were things that pained him. He was undoubtedly pained toward the end by the fact that his health was failing. I know he was pained by the pointless suffering of innocent people. But on the whole it seemed to me that he led the sort of life that would be ranked high by DAIAH. If so, he led a life that was good for him. His quality of life was high. Furthermore, in light of his apparent worthiness to have such a good life, DDAIAH implies that his living of that life made the world a better place. I think this is true, and I take pleasure in the fact that these forms of hedonism have these attractive implications.

\section{References}

Adams, Robert, Finite and Infinite Goods: A Framework for Ethics (New York and Oxford: Oxford University Press, 1999).

Alston, William, 'Pleasure', in Paul Edwards (ed.) The Encyclopedia of Philosophy (New York: Macmillan Publishing Co. \& The Free Press, 1967) vol. 6, pp. 341-347.

Aristotle, Nicomachean Ethics (Indianapolis and New York: Bobbs-Merrill, 1962).

Richard Brandt, Ethical Theory: The Problems of Normative and Critical Ethics (Englewood Cliffs: Prentice-Hall, Inc., 1959).

'Hedonism', in Paul Edwards (ed.) The Encyclopedia of Philosophy (New York: Macmillan Publishing Co. \& The Free Press, 1967) vol. 4, pp. 432-435.

A Theory of The Good and the Right (Oxford: The Clarendon Press, 1979).

'Two Concepts of Utility', originally published in Harlan B. Miller and William H. Williams (eds.), The Limits of Utilitarianism (Minneapolis: University of Minnesota Press, 1982); reprinted in Morality, Utilitarianism and Rights, pp. 158-175. 
1992).

Morality, Utilitarianism, and Rights (Cambridge: Cambridge University Press,

, Value and Obligation: Systematic Readings in Ethics (New York, 1961: Harcourt, Brace \& World, Inc.)

Broad, C. D., selection from Five Types of Ethical Theory reprinted in Value and Obligation: Systematic Readings in Ethics ed. by Richard Brandt.

Chisholm, Roderick M., Brentano and Intrinsic Value (Cambridge: Cambridge University Press, 1986).

Conee, Earl, Pleasure and Intrinsic Value Doctoral Dissertation submitted at the University of Massachusetts, 1980.

Epicurus, 'Letter to Menoeceus' in The Stoic and Epicurean Philosophers ed. and with an introduction by Whitney J. Oates (New York: Random House, 1940).

Feldman, Fred, 'Two Questions about Pleasure', in David Austin, (ed.) Philosophical Analysis (Dordrecht: Kluwer Academic Publishers, 1988), pp. 59-81. Reprinted in Utilitarianism, Hedonism and Desert.

,Utilitarianism, Hedonism and Desert: Essays in Moral Philosophy (Cambridge and New York: Cambridge University Press, 1997).

, 'Adjusting Utility for Justice: A Consequentialist Reply to the Objection from Justice' Philosophy and Phenomenological Research LV, 3 (September, 1995), pp. 567-585. Reprinted in Utilitarianism, Hedonism and Desert. Also reprinted in What Do We Deserve?: A Reader on Justice and Desert ed. by Louis P. Pojman and Owen McLeod, (New York and Oxford: Oxford University Press, 1999).

, 'Basic Intrinsic Value' Philosophical Studies 99,3 (June, 2000), pp. 319 - 346.

, 'Mill, Moore, and the Consistency of Qualified Hedonism' Midwest Studies in Philosophy, Volume XX: Moral Concepts ed. by Peter French, Theodore E. Uehling, Jr., and Howard Wettstein (Notre Dame, Indiana: University of Notre Dame Press, 1996), pp. 318-331. Reprinted in Utilitarianism, Hedonism and Desert.

, 'On the Intrinsic Value of Pleasures' Ethics 107 (April, 1997), pp. 448-466; reprinted in Utilitarianism, Hedonism and Desert.

Frankena, William, Ethics (Englewood Cliffs: Prentice-Hall, Inc., 1973).

'Value and Valuation' in Paul Edwards (ed.) The Encyclopedia of Philosophy (New

York: Macmillan Publishing Co. \& The Free Press, 1967) vol. 8, pp. 229-32. 
Goldstein, Irwin, 'Hedonic Pluralism', Philosophical Studies 48 (1985), pp. 49-55.

'Pleasure and Pain: Unconditional, Intrinsic Values', Philosophy and

Phenomenological Research L, 2 (December, 1989), pp. 255-276.

Hurka, Thomas, 'Virtue as Loving the Good', in The Good Life and the Human Good ed. by Ellen Frankel Paul, Fred D. Miller, Jr., and Jeffrey Paul (Cambridge: Cambridge University Press, 1992), pp. $149-168$.

Kagan, Shelly, 'The Limits of Well-being', Social Philosophy and Policy 9,2 (1992); reprinted in The Good Life and the Human Good ed. by Ellen Frankel Paul, Fred D. Miller, Jr., and Jeffrey Paul (Cambridge: Cambridge University Press, 1992), pp. 169 - 189.

, 'Me and My Life' Proceedings of the Aristotelian Society 94 (1994), pp. 309-324.

, Normative Ethics (Boulder, Colorado, 1998:Westview Press).

Lemos, Noah, Intrinsic Value: Concept and Warrant (Cambridge, 1994: Cambridge University Press).

Moore, G. E., Principia Ethica (Cambridge: Cambridge University Press, 1962; first published 1903). , Ethics (London, 1912: Oxford University Press).

'The Conception of Intrinsic Value', in Philosophical Studies (London: Routledge \& Kegan Paul, Ltd., 1960), pp. 253-275.

Nagel, Thomas, 'Death’ in Mortal Questions (Cambridge, 1979: Cambridge University Press), pp. 1-11.

Nozick, Robert, Anarchy, State and Utopia (New York, 1974: Basic Books).

Parfit, Derek, Reasons and Persons (Oxford, 1984: Oxford University Press).

Ross, Sir William David, The Right and the Good (Oxford, 1930: Oxford University Press).

Sidgwick, Henry, The Methods of Ethics (London: Macmillan \& Co. Ltd., 1972).

Sumner, L. W., review of Utilitarianism, Hedonism, and Desert in Ethics, October, 1998, pp. 176-179.

Zimmerman, Michael, 'On the Intrinsic Value of States of Pleasure', Philosophy and Phenomenological Research 41 (1980-81), pp. 26 - 45. 